\title{
EPIDEMIOLOGY OF EYE DISEASES AMONG TIMBER WORKERS IN OWERRI, NIGERIA
}

\author{
BY \\ ESENWA, E. C. \\ DEPARTMNET OF OPTICAL TECHNOLOGY, \\ OWERRI, IMO STATE, NIGERIA
}

\section{$\Lambda$}

ABSTRACT n epidemiological study of the Timber Industry in Owerri, Nigeria was carried out. It assessed the burden of eye diseases among Timber workers in terms of magnitude, causes and time. pinguecula and uveitis, each, accounting for $39.52 \%, 31.10 \%, 12.53 \%, 7.34 \%$ and $2.16 \%$ respectively, were found among the workers. The workers who have spent close to $16-20$ years in the industry recorded the highest prevalence $(21.92 \%)$ of the eye diseases, while those who have spent about 1-5years recorded the least prevalence of $4.57 \%$. The working environment was unsanitary and no worker wore any protective goggle. These two latter factors are believed to have contributed to the prevalence of these eye diseases among the workers.

KEYWORDS: Timber workers, eye diseases, work environment, prevalence, environmental pollutants.

\section{INTRODUCTION}

Man is primarily a visually motivated machine. This is because most of his daily tasks are dependent on healthy eyes for good vision. Indeed, North ${ }^{1}$ emphasized this point when he asserted that these daily tasks were dependent on man's visual capabilities and the visibility of the task.

Today many complex types of work take place in the timber industry. They include sawmilling, carving and carpentry, along with a good complement of workforce comprising timber owners, labourers, artisans, food vendors and visiting customers.

The timber industry generates a lot of environmental pollutants. They include sawdust, falling debris, flying objects (both wood and metals), chemicals used for wood processing and preservation, electric shocks, various types of fuel and gaseous emissions, each of which plays a part in the general health condition of the eye. Indeed they cause ocular problems.

Consequently, an epidemiological study of this nature enables us to assess the burden of eye diseases among timber workers, in terms of magnitude, cause(s), time, and place. The aim being to preserve healthy eyes and prevent blindiness ${ }^{2}$

This study became necessary following the recorded increase in the number of timber workers visiting some Eye Clinics in Owerri, for one eye problem or the other, followed closely by repeat visits.

\section{METHOD}

The Eye screening exercise was carried out at the site of business, i.e., inside the timber shade, using one of the standard rooms attached to the office of the Executive President of the Timber Traders Association, Owerri.

Using the stratified random sampling technique, 463 timber workers aged 1180 years were selected and screened. The screening exercise involved direct eye examination. The materials used included pen-torch, ophthalmoscope, head loupe, near and distant V.A. Charts both literate and illiterate, Shiotz tonometer, methylated spirit, cotton wool and all materials were cleaned and sterilized as appropriate.

\section{RESULTS}

Table 1 revealed the age distribution of the workforce. The highest workforce of $26.13 \%$ was found in the age group of 41-50 years, closely followed by the $31-40$ years age group with $25.70 \%$. The least workforce of $0.43 \%$ was found in the 71-80 age group. Table 2 shows the types of eye diseases seen among timber workers. Conjunctivitis (39.52\%) accounted for 
the highest eye disease, followed by foreign bodies/ trauma (31.10\%). Next was pterygium with $12.53 \%$ and pingueculum with $7.34 \%$. Uveitis and glaucoma had occurrence of $2.16 \%$ each followed by cataract $(3.23 \%)$ and retinal degeneration having the least occurrence $(1.95 \%)$.

Table 3 shows the distribution of different types of eye diseases with age. The age group 31-40 years accounted for the highest prevalence (26.23\%) of conjunctivitis, closely followed by the age group 21-30 (24.59\%). The age group 71-80 years accounted for the least prevalence (1.09\%). The age distribution of the prevalence of foreign bodies/trauma showed that age group 21-30 years accounted for the highest prevalence (28.47\%) followed by the age group 31-40years (25.0\%). Age group 71-80 years accounted for the least occurrence $(0.68 \%)$.

The highest prevalence of Pterygium (46.55\%), occurred in the 41-50 age group, followed by the age group 5160 with $31.03 \%$. The least prevalence of $3.45 \%$ was found in the $71-80$ age group. No Pterygium was seen in the age groups 11-20 and 21-30 (see table 3 ). The age group 31-40years accounted for the highest prevalence of pingueculum with $58.82 \%$ occurrence, followed by the age group 21-30 with $29.41 \%$ occurrence. The least prevalence of $11.76 \%$ occurred in the age group 41-50. its occurrence was not recorded in other age groups (table 3). Cataract occurrence (60\%) was highest among 61-70 age group followed by the age group 51-60 with $26.67 \%$. The least prevalence of $13.33 \%$ occurred in the age group 71-80 years while other groups had zero occurrences (table $3)$.

Uveitis was recorded only in age groups, $31-40,41-50$ and $21-30$ with $50.0 \%, 30.0 \%$ and $20.0 \%$ occurrences respectively. When distribution for glaucoma was considered, the prevalence was recorded only in age groups 41-50, 51-60 and 61-70 with $30.0 \%, 40.0 \%$ and $30.0 \%$ respectively. Retinal degeneration according to age was found in age groups 51-60, $61-70$ and $71-80$ with $22.22 \%, 55.56 \%$ and $22.22 \%$ prevalence respectively (table 3 ).

The relationship between the prevalence of eye diseases and work experience was also observed. This is represented in table 4. The highest prevalence of eye disease, $25.92 \%$ was found in the workers with 16-20 years work experience, followed by those with 11-15 years work experience with $21.60 \%, 21-25$ years work experience with $19.44 \%$ and the 6-10 years work experience with $15.12 \%$. The least prevalence was found in the workers with 1-5 years work experience $(4.57 \%)$ followed by those with 26 years and above work experience with $(12.96 \%)$.

\section{DISCUSSION}

The youngest workers in the Owerri timber industry were about 11 years old while the oldest were about 80 years. Based on interviews carried out on the workers, majority of those above 61 years tend to retire from the trade and move over to the village, while those in the 11-20 years age group were mostly a combination of school dropouts and people orphaned early in life. This may explain why these two age groups accounted for low prevalence of $5.61 \%$ and $6.70 \%$ respectively.

The highest percentage of the force is the age bracket 21-60 years. They collectively accounted for $87.69 \%$. In this age bracket, the number of workers peaked with $26.13 \%$ in the $41-50$ age group, closely followed by the 31-40 age group with $25.13 \%$ (see table 1). These two age groups collectively represent man's best productive years ${ }^{1}$. The least working population of $0.43 \%$ occurred in the 71-80 age group. Workers in this category were already "tired" and "slow". The few present had continued to carry on because there was no interested family member to take over their business just like their retired colleagues.

In the screened population of 463 workers, 8 different types of eye problems were seen. Pterygium $12.53 \%$, Pingueculum $7.34 \%$, Cataract $3.24 \%$, Uveitis $2.16 \%$, Glaucoma $2.16 \%$ and retinal degeneration $1.95 \%$ (table 2). The eye problems of significance here are conjunctivitis $(39.52 \%)$, foreign bodies/trauma (31.10\%) and pterygium (12.53\%).

Conjunctivitis has been reported to strive in dirty, unhygienic and unsanitary environment ${ }^{2}$. The typical timber shade environment is damp, messy and untidy with odours oozing out from wood and other decomposing organic materials, thereby creating very good and favourable habitat for flies, bacteria, fungi, viruses, algae and other microoganisms. Worse still, the place lacked pipe-borne water and good toilet facilities. Conjunctivitis affected mostly those in the 21-50years age bracket (see table 3). They accounted for about $68.31 \%$ of the eye infection. This could be attributed to the fact that this age bracket are those actually involved in the felling 
of trees, sawmilling with its attendant sawdust, lifting and transportation of planks on their heads, shoulders and bodies, and in the handling of machines and tools. Despite accounting for less than $7.0 \%$ of the working population, the teenage age group $11-20$ recorded $15.30 \%$ of the infection a reasonable percentage compared to their number. This may be attributed to their noticeable poor sense of personal hygiene. They were mostly casual labourers.

Table 2 reveals the number of cases of ocular foreign bodies/trauma. This accounted for $31.10 \%$ of all the eye problems recorded. They were found to be caused by flying particles of sawdust, wood and metals during the operations of machines mainly used for filing and/or sharpening of saw-blades, cutlasses, carving knives and cutting of logs and planks. Other causes included falling objects/debris, employee accidentally falling down and explosions ${ }^{5}$. The age bracket 21-50 years accounted for about $75.0 \%$ of the total ocular foreign bodies/injuries/traumas (table 4). Again, this is the age bracket in the forefront of production and consequently, the major risk group. These risk factors and risk age bracket are in total agreement with the work of Acheson et al ${ }^{6}$ and Noble and McFazdean ${ }^{7}$. Before then, Chiapelli and Rosenthal ${ }^{5}$ in 1985, carried out a study on 6,573 patients admitted at Leicester Royal Infirmary, U.K., $32.0 \%$ of the patients were found to have ocular injuries and trauma and the majority were in the 20-45 age group, which are in agreement with this finding.

Pterygium was found mostly in the age group 41-60 years. This class of workers accounted for over $77.58 \%$ of all the pterygium cases seen (see table 3 ). This may be attributed to the prolonged, cumulative and continuous presence of these categories of workers over the years at the work sites, where they are exposed to dust from sawdust, fumes/smokes from fuel and gases used for the powering of machines and provision of energy. Besides, they are at the mercy of sunshine under which they carry out their trade ${ }^{2}$. The finding of $31.03 \%$ of pterygium in the 51-60 years age group was high. This high prevalence may be attributed to age and the accumulation over the years, of desiccation, microtrauma and foreign bodies ${ }^{2}$.
The age groups $21-30$ with $29.40 \%$ and $31-40$ with $58.82 \%$, collectively accounted for about $88.23 \%$ of all the cases of pingueculum seen in the population (see table 3 ). The emergence of pingueculum, $29.41 \%$ in the age group 21-30 years and $0.0 \%$ for pterygium (see table 3 ) recorded for the same age group gives credence to the theory that pingueculum is a forerunner to pterygium ${ }^{2}$. The high prevalence of pingueculum recorded in these two age groups, 21-30 and 31-40 years, may be attributed to the fact that they are the workers actually involved in the day to day operations and direct handling of all types of machineries, tools, saw milling, grinding, buffing in the timber industry all of which are predisposing risk factors ${ }^{3}$.

All the cases of uveitis seen were as a result of injuries, trauma and foreign bodies. The 50.0\% of the disease observed in the 31-40 age group may be attributed to the accumulations of insults over the years to the eyes (table 3). Again, this is the age group involved in production in the industry. The drop from $50.0 \%$ of the disease to $30.0 \%$ in the next age group of 41-50 may be due to the resolution of the disease through medical treatment ${ }^{1}$.

The cases of cataract $(3.24 \%)$, glaucoma $(2.16 \%)$ and retinal degeneration $(1.95 \%)$ seen in the sample population had nothing to do with the work environment. They arose due to age factors (see table 3).

Table 4 revealed the near parabolic relationship between years of work experience and eye diseases. Eye disease rose gradually from $4.57 \%$ to peak at $25.92 \%$ and dropping gradually thereafter. This behavioural pattern is suggestive that the age groups from 21 to 50 years have work experience raging from 620 years. The drop in the frequency of linear progression observed after 20 years and above of work experience, is due to the fact that the workers aged 51years and above that collectively make up this working population are only $25.27 \%$. Besides, they are entrepreneur/elders who barely stay at the sites of operations. Their job is mainly supervisory and hence less exposure to risk factors. Awareness campaign should be carried out on eye health and hygiene for timber workers to help prevent blindness among the workers. 


\section{REFERENCES}

1. North, R.V. (1993): Occupational Optometry. $2^{\text {nd }}$ edn. Oxford University Press, Waltons Street, Oxford, pp 1- 49.

2. Johnson, G.J., Minassian, D.C., and Weale, R.A. (2003). The Epidemiology of Eye Diseases. $1^{\mathrm{st}}$ edn. Arnold publishers, 338 Euston Road, London, pp 3 - 90.

3. Miller, S.J.H. (1996): Parsons' Disease of the Eye. $18^{\text {th }}$ edn. Churchill Livingstone, Edinburgh, London. pp 128230.

4. Bisley, G.G. (1980): A Handbook of Ophthalmology for Developing Countries. $2^{\text {nd }}$ edn. Oxford University Press, Nairobi, pp 6-72.

5. Chiapella, A.P, and Rosenthal, A.R. (1985): One year in an Eye Casualty Clinic. Br. J. Ophthalmol., 69:865 70.

6. Acheson, J.F., Wong, D., and Chignell, A.H. (1987): Eye Injuries caused by direct jets of water from a fire hose. Br. Med. J., 292: 4812.

7. Noble, M.J., and McFazdean, R. (1987): Indirect Injury to the Optic Nerve and Optic Chiasma. Neuro. Ophthalmol., 7:341-8.

TABLE 1:AGE DISTRIBUTION OF WORKFORCE

\begin{tabular}{|l|l|l|}
\hline Age Group (yrs) & Frequency & \%Frequency \\
\hline $11-20$ & 31 & 6.70 \\
$21-30$ & 75 & 16.20 \\
$31-40$ & 119 & 25.70 \\
$41-50$ & 121 & 26.13 \\
$51-60$ & 91 & 19.66 \\
$61-70$ & 24 & 5.18 \\
$71-80$ & 2 & 0.43 \\
\hline Total & 463 & 100 \\
\hline
\end{tabular}

TABLE 2: TYPES OF EYE DISEASES RECORDED

\begin{tabular}{|l|l|l|l|}
\hline S/no & Disease & Frequency & \%Frequency \\
\hline 1 & Conjunctivitis & 183 & 39.52 \\
2 & Foreign & & \\
& bodies/traumas & 144 & 31.10 \\
3 & Pterygium & 58 & 12.53 \\
4 & Pingueculum & 34 & 7.34 \\
5 & Cataract & 15 & 3.24 \\
6 & Uveitis & 10 & 2.16 \\
7 & Glaucoma & 10 & 2.16 \\
8 & Retinal Degeneration & 9 & 1.95 \\
\hline & Total & 463 & 100 \\
\hline
\end{tabular}


ESENWA, E. C.

TABLE 3: AGE DISTRIBUTION OF EYE DISEASES

AMONG THE TIMBER WORKERS

\begin{tabular}{|c|c|c|c|c|c|c|c|c|}
\hline 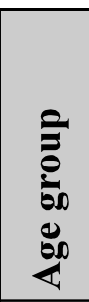 & ن & 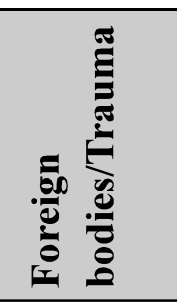 & 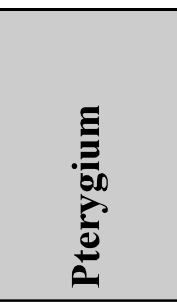 & 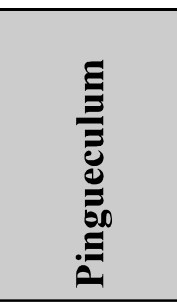 & 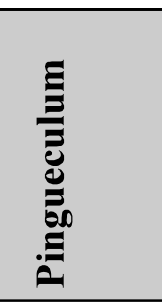 & 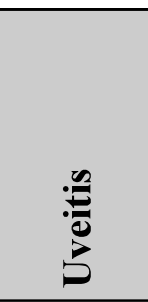 & 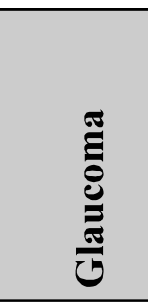 & 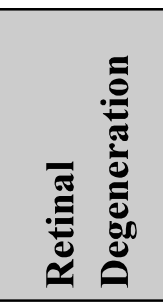 \\
\hline $11-20$ & $28(15.30 \%)$ & $27(18.75 \%)$ & - & - & - & - & - & - \\
\hline $21-30$ & $45(24.59 \%)$ & $41(28.47 \%)$ & - & $10(29.41 \%)$ & - & $2(20.0 \%)$ & - & - \\
\hline $31-40$ & $48(26.23 \%)$ & $36(25.0 \%)$ & $6(10.34 \%)$ & $20(58.82 \%)$ & - & $5(50.0 \%)$ & - & - \\
\hline $41-50$ & $32(17.49 \%)$ & $31(21.53 \%)$ & $27(46.55 \%)$ & $4(11.76 \%)$ & - & $3(30.0 \%)$ & $3(30.0 \%)$ & - \\
\hline $51-60$ & $22(12.02 \%)$ & $6(4.17 \%)$ & $18(31.03 \%)$ & - & $4(26.67 \%)$ & - & $4(40.0 \%)$ & $2(22.22 \%)$ \\
\hline $61-70$ & $6(3.28 \%)$ & $2(1.39 \%)$ & $5(8.65 \%)$ & - & $9(60.0 \%)$ & - & $3(30.0 \%)$ & $5(55.56 \%)$ \\
\hline $71-80$ & $2(1.09 \%)$ & $1(0.69 \%)$ & $2(3.45 \%)$ & - & $2(13.33 \%)$ & - & - & $2(22.22 \%)$ \\
\hline
\end{tabular}

TABLE 4: WORK EXPERIENCE AND EYE DISEASES

\begin{tabular}{|l|l|l|}
\hline Work Experience (yrs) & Frequency & \% Frequency \\
\hline 15 yrs & 23 & 4.57 \\
$6 \quad 10$ & 70 & 15.12 \\
11 & 100 & 21.60 \\
1620 & 120 & 25.92 \\
2125 & 90 & 19.44 \\
26 \& Above & 60 & 12.96 \\
\hline
\end{tabular}

